\title{
Poema
}

\section{la cortadura}

\author{
Raquel Salas Rivera
}

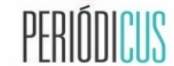

ISSN: 2358-0844

n. 15, v. 1

mai.2021-ago.2021

p. $98-109$

un extraterrestre finge

crecer yautías en casa de mi abuela;

un velociraptor consume gallinas;

una adivinación se escapa

de la jaula veraniega

de conocer a los primos.

a veces el único deseo reconocible

es materno

(mi madre diciéndome hija

a pesar de mis correcciones;

el cliché trans de la blusa

que me sirve pero no me queda.

aunque pienses que es un favor,

por favor, no quiero obsequios.)

con la anestesia,

se siente como una quemazón quitarme la ropa. 
quiero que mis amistades me quieran

¿pero como se hace eso?

que nunca me digan mija,

asuman que tengo a dónde irme

cuando la jeva me bota,

o que la madre que me da el abrazo

más abrazo del parque,

sepa que no hay continuidad

entre sus fotos

y los collages en mi estuche de emergencia:

los parchos contra el suicidio

si sobrevivo la pregunta

¿te gusta?,

sobreviviré

mi cumpleaños

en familia.

venirme

es tan complicado

como lograr

que digas mi nombre

con las manos.

lograr que digas mi nombre

es tan complicado

como venirme

sin que me toques.

una gallina cava un hueco

entre las raíces de la ceiba;

mi abuela le dice que hay café,

pero no quiere salir 
de la tierra.

las llamadas entran,

pero no sale de la casa.

no se asemeja a un entierro

estar tan adentrada,

más bien

la tierra es fría

cuando el calor es sofocante.

el calor del abrazo tan codiciado,

siempre es sofocante

porque quien da es igual a sí,

pero nunca igual a ti.

$\operatorname{XXXXXXX}$

si no entiendes que hablo de este género,

es porque no has visto las estadísticas que dicen

que es probable que no sobreviva

los cambios climáticos

que albergo en el pecho.

$\operatorname{XXXXXXXX}$

la palabra cortar

no debería aparecer en este poema,

sin que sepas

que me cuesta cada sílaba

de cada una de tus palabras

contestatarias.

$\operatorname{XXXXXXXXX}$

caigo entre los brazos

de quienes me aman,

justo a tiempo,

y rechazo su amor

Periódicus, Salvador, n. 15, v.1, mai.2021-ago.2021 - Revista de estudos indisciplinares em gêneros e sexualidades

Publicação periódica vinculada ao Núcleo de Pesquisa NuCuS, da Universidade Federal da Bahia - UFBA

ISSN: 2358-0844 - Endereço: http://www.portalseer.ufba.br/index.php/revistaperiodicus 
porque soy malagradecida.

por una palabra/

partida/

en mitades

que no me completan,

por un pronombre,

un adjetivo.

los requisitos para ser amadx

son: ser amada.

nunca seré amada,

aunque me amen.

a los 18 años escribí por primera vez:

no me quiero así,

pero así me quieres. 


\section{the cut}

Raquel Salas Rivera

an alien fakes

growing yautías at my grandmother's house;

a velociraptor eats chickens;

a prophecy escapes

the summer cage

of meeting one's cousins.

sometimes the only recognizable desire

is maternal

(my mother calling me daughter

despite my corrections;

the trans cliché of the blouse

that fits but doesn't look right.

even if you think it's a favor,

do me the favor: no gifts.)

with anesthesia,

taking off my clothes

feels like a sunburn.

i want my friends to love me,

but how does one do that?

i want them to never say mija,

assume i have somewhere to go

when my jeva kicks me out,

or that the mother that gives me

the strongest embrace in the park,

knows there's no continuity

between her photos

and the collages in my emergency kit:

patches against suicide.

Periódicus, Salvador, n. 15, v.1, mai.2021-ago.2021 - Revista de estudos indisciplinares em gêneros e sexualidades

Publicação periódica vinculada ao Núcleo de Pesquisa NuCuS, da Universidade Federal da Bahia - UFBA

ISSN: 2358-0844 - Endereço: http://www.portalseer.ufba.br/index.php/revistaperiodicus 
if $\mathrm{i}$ survive the question

do you like this?

i’ll survive

my family

birthday.

coming

is as complicated

as getting you

to say my name

with your hands.

getting you to say my name

is as complicated

as coming

without your touch.

a chicken digs a hole

amidst the ceiba's roots;

my grandmother says there is coffee,

but it doesn't want to come out

of the earth.

the calls come in,

but it doesn't leave the house.

to be so within

is not like a burial,

more like

the earth is cold

when heat suffocates.

the heat of the coveted embrace

Periódicus, Salvador, n. 15, v.1, mai.2021-ago.2021 - Revista de estudos indisciplinares em gêneros e sexualidades 
always suffocates

because the giver knows their self,

but never yours.

$\operatorname{XXXXXXX}$

if you don't understand i'm talking about this gender,

it's because you haven't seen the statistics that say

i probably won't survive

the climatic changes

i harbor in my chest.

$\operatorname{XXXXXXXX}$

the word cut

should not appear in this poem,

without you knowing

that each syllable

of every contestatory word,

costs.

$\operatorname{XXXXXXXXX}$

i fall in the arms

of those who love me

just in time,

and reject their love

because i am ungrateful.

over a word/

split/

in halves

that don't complete me,

over a pronoun,

an adjective.

Periódicus, Salvador, n. 15, v.1, mai.2021-ago.2021 - Revista de estudos indisciplinares em gêneros e sexualidades

Publicação periódica vinculada ao Núcleo de Pesquisa NuCuS, da Universidade Federal da Bahia - UFBA ISSN: 2358-0844 - Endereço: http://www.portalseer.ufba.br/index.php/revistaperiodicus 
the requirements for being amadx

are: being amada.

i’ll never be amada,

even if i’m loved.

for the first time, at 18, i wrote:

i don't want myself like this,

but this is the way you love me.*

* i don't love myself like this,

but this is the way you want me. 


\section{o corte ${ }^{1}$}

Raquel Salas Rivera

um extraterrestre finge

plantar yautías na casa de minha avó;

um velociraptor consome galinhas;

uma adivinhação escapa

da gaiola de verão

para conhecer os primos.

às vezes o único desejo reconhecível

$$
\text { é materno }
$$

(minha mãe me dizendo filha

apesar de minhas correções;

o clichê trans da camisa

que me serve mas não me cabe.

ainda que pense que é um favor,

por favor, não quero obséquios.)

com a anestesia,

se sente uma queimação

ao tirar a roupa.

quero que minhas amizades me amem

mas como fazer isso?

que nunca me digam minhafilha,

presumam que tenho para onde ir

quando a garota me expulsa,

ou que a mãe que me dá o abraço

mais abraço do parque,

saiba que não há continuidade

entre suas fotos

1 Traduzido por Carolina Hartfiel Barroso e Helder Thiago Maia. 
e as colagens em meu estojo de emergência:

os remendos contra o suicídio

XXXX

se sobrevivo à pergunta

gosta disso?,

sobreviverei

meu aniversário

em família.

XXXXX

gozar

é tão complicado

quanto conseguir

que diga meu nome

com as mãos.

conseguir que diga meu nome

é tão complicado

quanto gozar

sem que me toque.

uma galinha cava um buraco

entre as raízes da ceiba;

minha avó lhe diz que tem café,

mas não quer sair

da terra.

as chamadas entram,

mas não sai da casa.

não se parece com um enterro

estar tão internalizada,

mais como

a terra é fria

quando o calor é sufocante.

Periódicus, Salvador, n. 15, v.1, mai.2021-ago.2021 - Revista de estudos indisciplinares em gêneros e sexualidades

Publicação periódica vinculada ao Núcleo de Pesquisa NuCuS, da Universidade Federal da Bahia - UFBA ISSN: 2358-0844 - Endereço: http://www.portalseer.ufba.br/index.php/revistaperiodicus 
o calor do abraço tão cobiçado,

sempre é sufocante

porque quem dá é igual a si,

mas nunca igual a ti.

$\operatorname{XXXXXXX}$

se não entende que falo deste gênero,

é porque não viu as estatísticas que dizem

que é provável que não sobreviva

às mudanças climáticas

que abrigo no peito.

$\operatorname{XXXXXXXX}$

a palavra cortar

não deveria aparecer neste poema,

sem que saiba

que me custa cada sílaba

de cada uma de suas palavras

contestatórias.

XXXXXXXXX

caio entre os braços

daqueles que me amam,

bem a tempo,

e rechaço seu amor

porque sou mal agradecida.

por uma palavra/

partida/

em metades

que não me completam, 
por um pronome,

um adjetivo.

$\operatorname{XXXXXXXXXX}$

os requisitos para ser amadx

são: ser amada.

nunca serei amada,

ainda que me amem.

aos 18 anos escrevi pela primeira vez:

não me amo assim,

mas é assim que você me ama. 